\title{
La ovinocultura de lana en el extremo sur gaúcho': desafíos para la construcción de una cadena de valor
}

Sheep wool production in the extreme south of Brazil: challenges of a value chain construction

\author{
Eduardo Garcia Souza \\ Universidad Federal de Pelotas, Brasil \\ admeduardogarcia@gmail.com
}

Flávio Sacco dos Anjos

Universidad de Córdoba, España

saccodosanjos@gmail.com

\section{Resumen:}

Este artículo analiza las actividades productivas relacionadas con la producción de lana ovina, bajo la óptica de dos organizaciones localizadas en Jaguarão, extremo sur de Brasil. El objetivo fue identificar los principales desafíos enfrentados por los actores sociales desde el punto de vista organizativo, así como las estrategias de comercialización y de agregación de valor. La investigación fue efectuada a través de entrevistas con guion semiestructurado. Los desafíos que se imponen son los de cualificar a los productores para atender los mercados más exigentes y construir un espíritu de cooperación que supere la actuación individualista dominante en la región.

Palabras clave: Ovinocultura, Brasil, Cadenas de valor, Cooperativismo.

\section{Abstract:}

This article analyzes the productive activities related to the sheep wool production from the perspective of two organizations located in Jaguarão-RS, south end of Brazil. The objective was to identify the central challenges faced by the social actors from the organizational point of view, as well strategies of commercialization and value aggregation. The research was achieved through semi-structured interviews. The challenges are to qualify the product to meet rigorous markets and build a cooperative spirit that surpasses the individualistic action in the region.

KEYWORDS: Sheep procution, Brazil, Value chains, Cooperativism.

\section{INTRODUCCIÓN}

La producción de lana es una actividad secular en el sur de Brasil, que está ligada al bioma pampa, que cubre casi dos tercios de la superficie territorial del estado de Rio Grande do Sul. La importancia de la lana no es solamente económica; es, sobre todo, social y cultural. Además, desde mediados de los años 1980 se constata un declive intenso de esta actividad, muy en función de la ascensión de los tejidos sintéticos que, a pesar de presentar un costo de producción comparativamente más bajo, son bastante inferiores en términos cualitativos.

La crisis de la lana hizo que se produjese una reducción brutal en el efectivo de ovinos en Rio Grande do Sul. Parte de los productores abandonó la ovinocultura de lana, mientras otros se dedicaron a la producción de carne ovina o a otras actividades productivas. En el municipio de Jaguarão, en el extremo sur gaúcho, esta realidad se impuso de forma inequívoca. Aun así, algunos productores resistieron a la propia desaparición. Buena parte de ellos está ligada a una cooperativa que surgió hace más de 60 años para organizar una producción que vivía su auge, delante de una elevada demanda nacional y, sobre todo, internacional, de lana natural. La otra organización local en la que nos fijamos es la Associação dos Artesãos de Jaguarão, que integra 
a mujeres que se dedican a la producción de artículos de excelencia y de alto valor agregado utilizando lana ovina.

Estudiar estas organizaciones nos colocó delante de aspectos ligados con los dilemas y desafíos del desarrollo, asunto sobre el cual hay una controvertida y extensa producción científica y académica. Además de esta introducción, este artículo se subdivide en otras siete partes. La primera describe los aspectos metodológicos de la investigación. La segunda propone una revisión sobre el concepto de desarrollo. La tercera parte discute el tema de las estrategias que utilizan activos específicos de la región como fundamento para el desarrollo. El escenario de la ovinocultura en Rio Grande do Sul es abordado en el cuarto apartado. La quinta y la sexta parte realizan un análisis crítico de las dinámicas de las dos aludidas organizaciones, a la luz de las teorías del desarrollo. La séptima y última sección expone las consideraciones finales de la investigación.

\section{Aspectos Metodológicos}

Esta investigación se basa en un enfoque eminentemente cualitativo, en el cual se hizo uso de entrevistas (16) en profundidad, por medio de un guion semi-estructurado, incluyendo cuestiones abiertas y cerradas, aplicadas junto a los actores sociales ligados a las dos organizaciones mencionadas anteriormente: la Cooperativa de Lãs Mauá y la Associação dos Artesãos de Jaguarão. Las entrevistas se realizaron entre los meses de julio y septiembre del 2017, y fueron grabadas y transcritas integralmente para su sistematización y análisis. Diez (10) entrevistas fueron realizadas con artesanas locales, cinco (5) con ovinocultores miembros del cuadro asociativo de la cooperativa y una (1) entrevista con una funcionaria del servicio de extensión rural oficial (Emater), cuyo trabajo está directamente ligado con las organizaciones en cuestión.

La definición de la muestra ha sido elaborada desde una perspectiva no probabilística, mucho más adecuada para estudios exploratorios que llevan en cuenta la naturaleza del objeto de investigación y el esfuerzo por asegurar la representatividad del universo social bajo estudio. Las indicaciones de los agentes de la Emater del estado de Rio Grande do Sul ha sido fundamental en la indicación de los productores de ovinos para hacer las entrevistas. También se tuvo en cuenta el esfuerzo por encontrar sujetos adecuados, a los que se pidió que sugiriesen individuos similares que pudiesen prestar su tiempo y disposición para responder las cuestiones propuestas. No tuvimos impedimentos de cualquier naturaleza a la hora de obtener sus testimonios, incluso en temas sensibles como las cuestiones ligadas a comportamientos oportunistas de algunos cooperativistas cuya situación examinaremos en los párrafos subsecuentes.

Además, las incursiones en los locales de trabajo de los entrevistados permitieron, por medio de la observación participante, confrontar el discurso de los actores entrevistados con la realidad local. La utilización de fuentes documentales, así como los datos suministrados por los entrevistados, fueron igualmente fundamentales para la interpretación de este escenario. Por medio del análisis del contenido, las informaciones recolectadas en las entrevistas fueron evaluadas con el fin de verificar el grado de recurrencia en los argumentos que aparecían en las declaraciones de los actores sociales, con el objetivo de comprender algunos aspectos específicos de cada organización y otros, de carácter más general, sobre la coyuntura de la lana en el estado de Rio Grande do Sul. Entre los principales aspectos relevados constan los que afectan al funcionamiento de la comercialización local, la manera como las relaciones sociales se construyen, las posibilidades de renta presentes en los trabajos desarrollados y las perspectivas de estas actividades bajo la óptica de los actores sociales locales.

\section{ASPECTOS SOBRE LA EVOLUCIÓN DEL CONCEPTO DE DESARROLLO}

Desarrollo no es un concepto nuevo, así como las controversias que este término acarrea, ya sea en el ámbito del debate puramente académico, ya sea en términos de la agenda de las políticas públicas llevadas 
a cabo por las agencias nacionales e internacionales. Su carácter multidisciplinar y transversal da margen a diversas interpretaciones y significados, dependiendo del punto de vista desde el cual la realidad está siendo analizada. En este sentido, rescatamos algunos aspectos que ayudan a situar la discusión, así como sus implicaciones más relevantes dentro del marco de una actividad profundamente afectada por la marcha de la economía nacional y mundial. Esto es señalado porque el objetivo del estudio está orientado precisamente a la lana y la ovinocultura en general, su presente y, sobre todo, su futuro, contexto que acaba por recolocar el tema del desarrollo dentro de una región donde esta actividad es ejercida tradicionalmente.

Inicialmente, es interesante distinguir dos nociones o conceptos: progreso y desarrollo. Según Bresser Pereira $(2014,3)$, el "progreso es una idea y una aspiración del siglo XX que continúa en el siglo XXI". La idea de progreso, iniciada durante el iluminismo y colocada por Augusto Comte como uno de los principios fundamentales que deberían regir una sociedad, trae consigo el ideal de la razón por intermedio de la ciencia y de la tecnología como pilares centrales de la evolución social. Tal acepción también carga la idea de acumulación de riqueza material, asociada al bienestar alcanzado por Europa en franca oposición al atraso constatado por los países del tercer mundo (Furtado, 2013). Así, las diferencias culturales pasan a ser sistemáticamente ignoradas. Este parámetro imputa un carácter anacrónico a los países de la periferia del capitalismo central, como es el caso de Brasil.

El desarrollo, desde un punto de vista eminentemente económico, surge como un sustituto a la noción de progreso tras el final de la Segunda Guerra Mundial (Bresser-Pereira, 2014). Según Escobar (2007), las condiciones precarias de los países del Tercer Mundo quedaron evidentes después del final del conflicto bélico. La pobreza y el malestar vividos en algunos de esos países se volvió una enfermedad que debía ser curada bajo el empuje del crecimiento económico. La idea de desarrollo, en este sentido, usa los mismos fundamentos que la idea de progreso. Las clasificaciones entre los países (desarrollado o no desarrollado, central o periférico, primer mundo o tercer mundo, avanzado o atrasado) estaban basadas en indicadores económicos y/o en el nivel de industrialización (Silva, Nelson, Silva, 2017); En este sentido, el desarrollo estaba ligado a los altos niveles de urbanización. La dicotomía subyacente de este discurso identificaba a los países atrasados como aquellos en los que la economía estaba basada esencialmente en la agricultura, mientras que el ámbito urbanoindustrial era visto como el sector económico dinámico (Sacco dos Anjos, 2016). De esta forma, los países llamados atrasados deberían modernizarse por intermedio de un proceso de industrialización. Según Sachs (2005), tanto el bloque soviético como los países occidentales tenían una receta parecida: los países periféricos deberían quemar etapas en el proceso de modernización, priorizando la industrialización de base como el camino para el desarrollo.

Durante mucho tiempo y en muchas sociedades, tales tesis se impusieron en la actuación de las agencias de desarrollo. Los problemas ambientales eran vistos como efectos colaterales de un proceso que no podría ser interrumpido. No obstante, tal modelo trajo consigo desastrosas consecuencias. Reproducir los padrones de consumo de los países desarrollados era, y seguirá siendo, un verdadero mito, como bien expresó Celso Furtado. El reconocimiento de la importancia de la dimensión ambiental, iniciado a comienzos de la década del 1970, constituyó un marco importante en ese debate y en la construcción de un nuevo paradigma. El desarrollo pasaría ahora a cargar el adjetivo de "sustentable", que objetivaba la advertencia sobre la necesidad de implantar estrategias que instituyesen la centralidad de las cuestiones ambientales en la matriz de los proyectos de desarrollo. Este término surgió inicialmente en Estocolmo, en la Conferencia de Naciones Unidas sobre el Medio Ambiente Humano (CNUMAH), también conocida como Conferencia de Estocolmo (Veiga, 2005). No raras veces, la preservación de los recursos naturales es colocada como antagónica o un obstáculo para el desarrollo económico y social. En este sentido, a pesar de no centrar su mirada en la cuestión ambiental, el economista Amartya Sen (2007) es uno de los grandes responsables de permitir una interpretación actualizada del concepto global de desarrollo. Para Sen, este ha de ser visto como un proceso de expansión de las libertades individuales. Los individuos deben tener la capacidad de actuar en sus comunidades, de manifestar sus deseos y obtener condiciones dignas de vida. Para ello, es necesario 
ampliar las oportunidades de trabajo y los servicios de salud e infraestructura, además de disponer de libre acceso a los mercados y a un conjunto de estructuras de ascensión social.

Desde el punto de vista de las estrategias de desarrollo, el reconocimiento de las limitaciones del enfoque sectorial, centrado en apoyar cadenas productivas específicas, viene siendo fuertemente cuestionado desde mediados de los años 1980. El surgimiento de la idea de multifuncionalidad rural, en el auge de los años 1990, inaugura un importante debate en los países europeos, cuya influencia recae sobre América Latina (Sacco don Anjos, 2016) en la actuación de las agencias de desarrollo.

Según este enfoque, los espacios rurales o no densamente urbanizados no pueden ser relegados a funciones centradas únicamente en la producción de commodities agrícolas. Es que la sociedad pasa a demandar otros papeles ligados a la valorización de activos territoriales (cultura, gastronomía, turismo, etc.), así como la preservación de la biodiversidad. El abordaje territorial del desarrollo, además de reconocer estos aspectos, busca eliminar las dicotomías establecidas entre los sectores modernos y atrasados de la sociedad. Para el antropólogo Néstor García Canclini (1990), no hay una relación dialéctica entre lo tradicional y lo moderno. Estos dos conceptos no son lados opuestos sino elementos que se complementan recíprocamente.

Según Benko y Pecqueur (2001), "Contrariamente a las predicciones más sombrías, los 'territorios' con sus singularidades no son apagados bajo los flujos económicos de la mundialización” (p. 38, comillas en el original). Un ejemplo de la actuación complementaria de estos dos circuitos económicos, aparentemente antagónicos, son las actividades turísticas ligadas a productos tradicionales. Como explica García Canclini (1990), los productos tradicionales, además de generar rentas para los campesinos que los fabrican, desarrollan el turismo por medio de la atracción de los consumidores que encuentran, en esos productos, un signo de distinción y originalidad. Tales estrategias se asientan en dos pilares: de un lado, la valorización de los activos específicos de los territorios; de otro, la constitución de una red de relaciones que dé soporte a estas iniciativas. Procuramos abordar estos dos controvertidos temas a continuación.

\section{DESARROLLO TERRITORIAL, ACTIVOS ESPECÍFICOS Y CAPITAL SOCIAL}

Valerse de la identidad territorial para promover el desarrollo requiere establecer una conexión entre las especificidades del de la región (productos típicos, tradiciones, etc.) y los mercados. Este proceso incide no solamente en la valorización de bienes materiales sino que también afecta a los aspectos simbólicos, ligados a la identidad cultural de los territorios. Estrategias como esta pueden estar ligadas a la geografía del local, a la ecología, a la identidad étnica, a la historia, a la arquitectura, a las tradiciones y a las fiestas religiosas, etc., y son especialmente interesantes para las regiones rurales marcadas por el aislamiento y el estancamiento estagnación, al promover crecimiento en términos de renta y cohesión social (Fonte y Ranaboldo, 2007).

Según Benko y Pecqueur (2001), la búsqueda por la diferenciación del territorio debe priorizar los activos y los recursos específicos en detrimento de los genéricos. La materia prima y la mano de obra no cualificada son ejemplos de recursos genéricos, los cuales, al ser explotados, ganan valor comercial y se convierten en activos genéricos. Según Pecqueur (2009), este tipo de activo no se traduce en una diferenciación para el territorio, pues es fácilmente transferible de una región para otra y posee un valor de cambio relativamente bajo. Por otro lado, los activos específicos son aquellos que presentan características particulares vinculadas al local de origen, lo que eleva el costo de transferencia entre localidades. Con atributos exclusivos reconocidos, estos activos se traducen en una diferenciación duradera para el territorio que no queda susceptible a la variabilidad de los factores y a la banalización.

Así, la especificación de activos territoriales puede tornarse un buen camino para la valorización de las ventajas del territorio y contribuir, de este modo, a cualificar estrategias de desarrollo territorial (Dallabrida, 2012). Esto significa explotar las especificidades locales con el fin de promover una diferenciación productiva vinculada y enraizada en el territorio, o sea, orientar la producción local para un "modelo de calidad" en 
contrapunto al "modelo de productividad", preservando, así, la lógica de los territorios, en contraste con la lógica de las firmas (Pecqueur, 2009).

El desafío está en crear formas inteligentes de explotar estos activos, con el fin de promover externalidades positivas para el territorio que ampara la producción y para los actores sociales involucrados en los procesos productivos. Algunos estudios deben ser vistos como intentos de (re)valorizar los productos locales en general, mediante la construcción de marcas colectivas o por intermedio de indicaciones de procedencia (Belas y Wilkinson, 2014; Maiorki y Dallabrida, 2015; Sacco dos Anjos, Silva y Pollnow ,2016). Sin embargo, lo que ha sido empíricamente observado es que algunas dificultades son recurrentes en esta construcción. La baja capacidad de movilización de los actores sociales involucrados y la preponderancia de comportamientos oportunistas son, muchas veces, barreras insalvables encontradas a lo largo del camino. Otro punto aludido por Dallabrida (2016) es el hecho de que, en general, a pesar del mayor dinamismo económico encontrado en las regiones que adoptan tales estrategias, existe una carencia de solidaridad y una cultura de individualismo, así como "el hecho de que las experiencias de especificación de activos territoriales se tratan, mucho más, de negocios lucrativos privados que utilizan la estrategia del asociativismo para hacerse viables" (Dallabrida, 2016, 205).

Aun así, tales iniciativas pueden ser muy positivas en términos de generación de renta. Pese a todo, es necesario adoptar ciertos cuidados para que no se produzca el efecto inverso, el de generar la exclusión de los productores que no tienen condiciones para cumplir determinadas exigencias por la certificación, con lo que se quedarían al margen del proceso (Acampora y Fonte, 2007). Según Acampora y Fonte (2007), el éxito de estas estrategias está directamente conectado a la capacidad local de crear asociaciones de productores, de asegurar formas de certificar y proteger la calidad de los productos, que son así convertidos en activos específicos del territorio. Alcanzar este objetivo no es tarea fácil. Exige la actuación combinada de fuerzas endógenas y exógenas del territorio, así como la presencia de capital social (Fonte y Ranaboldo, 2007).

El abordaje del capital social es bastante esclarecedor, en el sentido de buscar explicaciones sobre cómo tales iniciativas prosperan y se consolidan. Según Abramovay (2004), la economía no puede ser interpretada como una esfera autónoma de la vida social, pues ella está imbricada en una estructura de relaciones sociales que influyen directamente en los aspectos económicos. Podría decirse que esta concepción es un contrapunto a la idea del homo economicus, sujeto que actúa unilateralmente mediante la selección racional, persiguiendo el mayor beneficio resultante de sus acciones (Ortega y Matos ,2013). Al contrario, el capital social ayuda a entender que los individuos no actúan de forma independiente y estableciendo objetivos solamente a través de un comportamiento egoísta. Hay por detrás de ellos una estructura social de la que pueden disponer (Abramovay, 2000).

El trabajo de Putnam en Italia constituye un marco en los estudios sobre el capital social. Según Putnam (2009), las diferencias de desempeño económico e institucional encontradas en las diferentes regiones italianas eran el resultado de la acumulación de capital social. Así, las regiones con mayor participación cívica y más organizaciones asociativas eran las que demostraban un mejor desempeño, al poseer un capital social más elevado, mientras que las de menor capital social presentaban un desempeño inferior. Estas regiones "menos cívicas", según Putnam (2009), cuentan con una vida social marcada por la fragmentación, el aislamiento y la desconfianza. En estos términos, un mayor capital social supone comportamientos pautados en la solidaridad de los miembros de la comunidad, en la confianza mutua y en la reciprocidad (Putnam, 2001). La construcción de estos lazos elimina la necesidad de contratos formales, pues la confianza genera un comportamiento recíproco, minimizando los vicios de comportamientos oportunistas, lo que permite a la comunidad cívica prosperar. De este modo, un desarrollo virtuoso sería el resultado de elevados niveles de cooperación, confianza y reciprocidad, y de la capacidad de la sociedad de organizarse, buscando el bienestar colectivo (Ortega y Matos 2013). Antes de analizar cómo estos elementos se presentan en el escenario bajo análisis, conviene hacer ahora una aproximación sobre la evolución y la situación de la ovinocultura gaúcha. 


\section{La ovinocultura en Rio Grande do Sul}

La ovinocultura es una actividad histórica y de gran relevancia económica y social en la región de la pampa gaúcha. Introducidos en Rio Grande do Sul por intermedio del proceso de colonización española, los ovinos posibilitaron el desarrollo de una serie de actividades productivas. Su gran capacidad de adaptación y sus diferentes utilidades, especialmente la producción de carne y de lana, tanto para la explotación comercial como para el autoconsumo de las familias rurales, hizo que la ovinocultura se convirtiera en una de las grandes marcas de Rio Grande do Sul en los siglos XIX y XX.

La demanda por lana generada en los países europeos, sobre todo durante la Primera Guerra Mundial, hizo que se ampliase la producción gaúcha de lana, valorizando una actividad que, hasta entonces, era destinada primordialmente al mercado interno. Organizados en cooperativas de lana, los productores rurales buscaban aumentar su escala de producción y tener más autonomía para negociar con los países importadores (BOFFIL, 1996). Con la lana en alta y los productores organizados en torno de esta actividad, la producción lanar elevó su grado de importancia en términos de volumen de comercialización. Del periodo de inicio de las cooperativas (1914-1915) hasta la década de 1970, la ovinocultura experimentó un gran apogeo, tanto en términos de volumen como desde la óptica del valor comercial.

El gran cambio en este escenario ocurrió en el final de esa misma década (1970) e inicio de los años 1980. Este punto de inflexión se da con la crisis de la lana, ocasionada especialmente tras la entrada de tejidos sintéticos en los mercados (Viana y Waquil ,2013). El precio más atractivo de las fibras artificiales propició la obtención de tejidos más baratos, aunque con una calidad inferior. Este hecho afectó duramente al sector y contribuyó a la migración de los ovinocultores para otras actividades; y lo llevó a un declive acentuado de los efectivos que, desde entonces, no ha cesado sino que se agudiza en la última década.

Los datos de la Figura 1 ofrecen una visión muy clara de lo que pasó con la ovinocultura de Rio Grande do Sul, el estado que durante mucho tiempo fue el más importante del país en esta actividad productiva. En efecto, según los dados de los sucesivos censos agropecuarios, el plantel de 12,157 millones de cabezas que había en 1970 se redujo a 2,646 en el año 2017, o sea a 21,8 \% de lo que había en 1970. Son datos que revisten importancia a causa de los cambios que afectan duramente a un sector que fue tan importante para la economía de Rio Grande do Sul, y por supuesto, de Jaguarão, el municipio que representa el contexto empírico de nuestro estudio.

La información representada en la Figura 2 indica la evolución de la producción de lana en Rio Grande do Sul durante el mismo período (1970-2017) a partir de los datos de los censos agropecuarios. Como se puede ver, en 1970 fueron producidas 33,21 miles de toneladas de lana en esta unidad federativa que aisladamente concentraba, a la sazón, el 98,8 \% por ciento de la producción nacional. Pues en 2017 la producción se había reducido a escasas 6,82 miles de toneladas, lo que equivale a 20,5\% de lo que se había producido en 1970. 
FIGURA 1.

Evolución del efectivo de ovinos (cabezas) entre 1970 y 2017 en Rio Grande do Sul

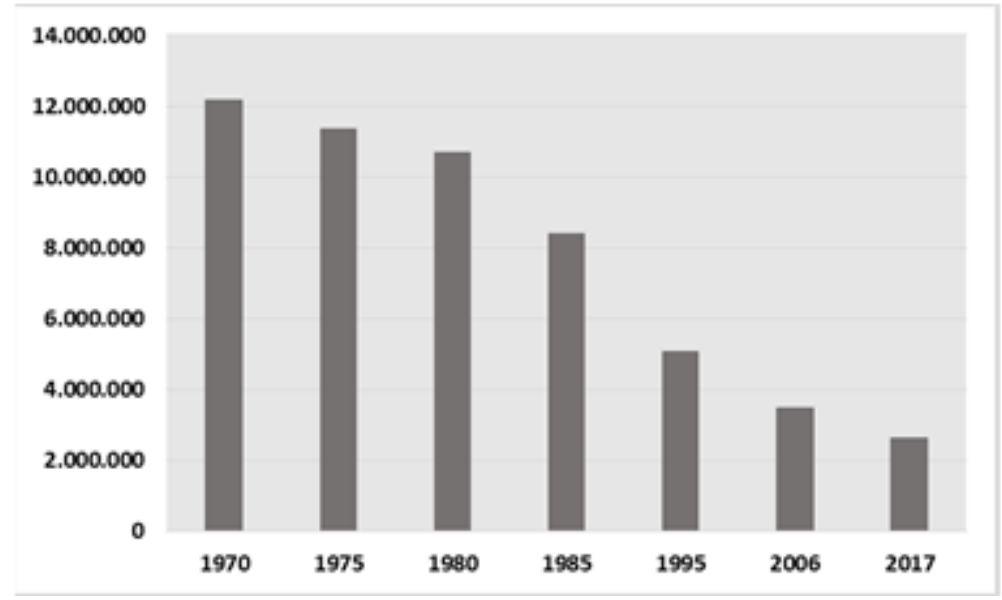

Fuente: Censos Agropecuarios (IBGE)

FIGURA 2.

Evolución de la producción de lana de Rio Grande do Sul entre los años 1970 y 2017

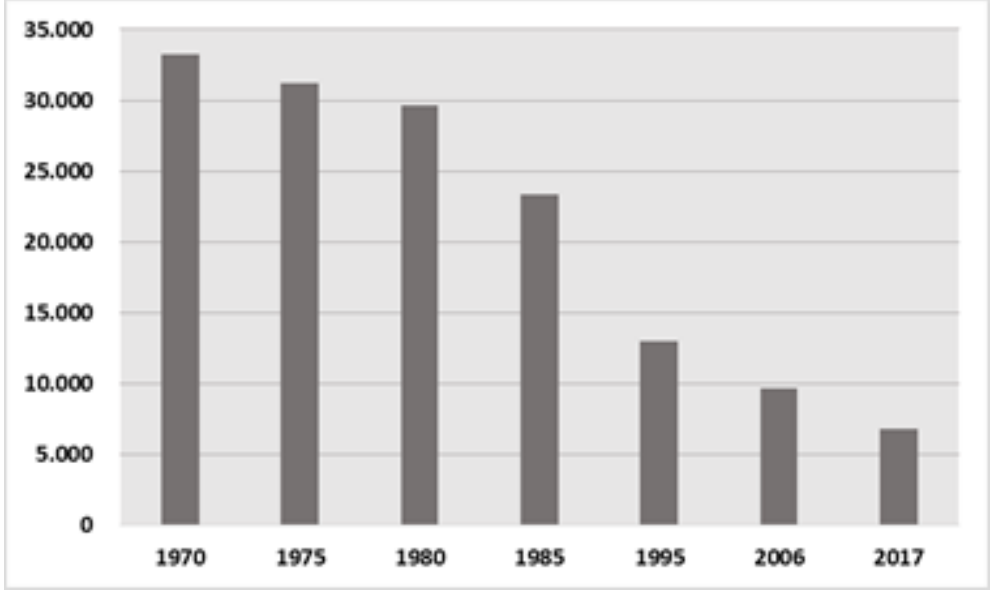

Fuente: Censos Agropecuarios (IBGE)

Los datos que aportamos a este estudio acompañan claramente lo que ha pasado en otras latitudes al nivel mundial. Un estudio realizado por Morris (2009) describe en detalle la evolución de la producción mundial de ovinos, mostrando que el número de animales ha disminuido drásticamente en todo el mundo, no obstante algunos avances tecnológicos relevantes, como el incremento en el número de partos de ovejas madres, que pasó del $98 \%$ en 1987 al $125 \%$ en 2008. No obstante, incluso en países donde dicha actividad ha avanzado técnicamente de forma notable, como Nueva Zelanda y Australia, se asiste a un proceso de profesionalización que va dejando por el camino muchas explotaciones incapaces de resistir las presiones mercadológicas. Como bien subraya Morris (2009), los criadores se enfrentan a una serie de desafíos, incluyendo el cambio climático y la mitigación de los gases de efecto invernadero, todo lo cual potencialmente tendrá un impacto en la rentabilidad futura y, por lo tanto, en el futuro de dicha actividad.

El cuadro de la ovinocultura de Rio Grande do Sul, a grandes rasgos dibujado, refleja una situación que impacta duramente en el ámbito de los pequeños municipios y localidades rurales, no solamente desde el prisma económicosino especialmente desde el prisma social y cultural. Labores y oficios ligados a la ovinocultura paulatinamente van desapareciendo y dejan lugar a la incertidumbre y a una crisis de expectativas. Una ínfima parcela de los productores persiste, pero ahora dirigiéndose a otras actividades, como 
la producción de carne de cordero. En estos términos, la lana se convierte en un artículo secundario. Otro aspecto que merece ser destacado es la pérdida de protagonismo de la ovinocultura de Rio Grande do Sul. Es que otras unidades federativas ampliaron su participación, aunque las razas son muy distintas de las que existen en el sur del país, así como los sistemas productivos. La información reunida en la Tabla 1 indica que en 1970 el estado de Rio Grande do Sul acaparaba el 68,9\% del rebaño ovino nacional. Sin embargo, en 2017 dicha cifra se ha reducido hasta un escaso $19,2 \%$, lo que es igualmente muy significativo.

TABLA 1.

Evolución del efectivo ovino en Rio Grande do Sul y Brasil entre los años 1970 y 2017

\begin{tabular}{|l|c|c|c|c|c|c|c|}
\hline & 1970 & 1975 & 1980 & 1985 & 1995 & 2006 & 2017 \\
\hline Rio G. do Sul & 12.157 .357 & 11.361 .709 & 10.696 .237 & 8.394 .915 & 5.081 .387 & 3.477 .062 & 2.646 .969 \\
& & & & & & & \\
\hline
\end{tabular}

Fuente: Censos Agropecuarios (IBGE)

\section{Resultados Y DISCUSIÓN: DESAFíos Y PERSPECTIVAS EN EL COMERCIO COOPERATIVO DE LANA}

La Cooperativa de Lanas Mauá fue creada en 1952 con la finalidad de reunir a los ovinocultores de Jaguarão y cercanías para organizarlos y comercializar conjuntamente la lana producida en sus propiedades. Casi siete décadas después, la organización aún se mantiene activa en el mercado de lana. Sin embargo, la dimensión de su cuadro social se redujo sensiblemente. Como la Cooperativa de Lana Tejupá, localizada en São Gabriel, es una de las últimas cooperativas de lana de Rio Grande do Sul que todavía permanecen en actividad. La actuación de la Cooperativa Mauá contempla esencialmente la tarea de recepción de la producción de los productores asociados, además de la clasificación y almacenamiento de acuerdo con el grado de finura de la fibra, que es posteriormente vendida, tanto para la industria nacional como para la exportación. La cooperativa, además, mantiene una tienda adjunta de productos veterinarios en donde se almacena la lana. La actividad lanar es de carácter marcadamente estacional, ya que la esquila se produce normalmente entre la primavera y el verano, en los meses de octubre, noviembre, diciembre y enero.

El modelo de comercialización de cooperativa se mantiene básicamente igual al de la época de su fundación. Sin embargo, la aguda crisis que vivió la ovinocultura orientada para la lana en la década de 1980 trajo repercusiones que impactaron profundamente en esta actividad. La reducción en los volúmenes comercializados hizo que disminuyese, drásticamente, el número de productores y de asociados de la cooperativa. Hasta mediados de los años 1970 la cooperativa encontraba, en los mercados europeos y asiáticos, el destino principal de su producción, que actualmente está restringida a la exportación de pequeñas cantidades para el vecino Uruguay, con el cual Jaguarão limita.

En los períodos de prosperidad económica y de valorización de la fibra, la organización creció vertical y horizontalmente, ampliando su patrimonio inmovilizado e instalando unidades en municipios vecinos como Herval y Arroio Grande. Para los productores, este comercio se traducía en más renta para las familias, las cuales utilizaban el dinero generado con la venta de lana para suplir las demandas de la propiedad, adquirir bienes de consumo duradero y asegurar su reproducción social. Las declaraciones de los entrevistados nos ayudan a captar la dimensión que la producción de lana asumía, a la sazón, para la vida cotidiana de estas familias. 
Según el Cooperativista ${ }^{2}$ 2: "En aquella época las personas compraban de todo con el dinero de la lana, mantenian la hacienda, la prosperidad, comida, ropa, de la lana salia para toda la propiedad". Otro entrevistado también refuerza este aspecto: "El gasto de alli fuera todo era con la lana. La comida para nosotros aqui en la ciudad, la comida fuera, todo con el valor de la lana" (Cooperativista 5). Como se dijo anteriormente, el escenario se modificó de manera contundente con el paso del tiempo. El cambio de la ovinocultura de lana para la producción de carne es parte de este cuadro de modificaciones.

Hasta la década de los ochenta era una vida, la oveja de la década de los ochenta para acá mudó todo. Del agua para el vino. Solo que la lana de la década de los ochenta, como es que puedo decírtelo, el principal producto de la oveja era la lana. Hoy en día para mí la lana es casi un subproducto, yo creo mucho más en la carne que en la lana. Porque después que entró el sintético, el hilo sintético cambió mucho. (Cooperativista 1)

El cambio de contexto de consumo (de la fibra orgánica para la sintética) no solo disminuyó la oferta general, en términos de cantidad de lana producida, sino que redujo la capacidad de suministro de aquellos que comercializaban la producción. Delante del contexto actual, surgen grandes desafíos para el presente y el futuro de la cooperativa. Además, esto es sólo una faceta de los problemas. Buena parte de las actuales dificultades vividas en el día a día de la cooperativa es el resultado de las fragilidades del capital social de una actividad y de una región marcada por el elevado grado de aislamiento.

La capacidad de organización y el desempeño organizativo son debilitados por la falta de interés y participación de los socios en asuntos institucionales. El estudio de Desimon y Novello (2013), realizado en este mismo contexto, demostró indicios de un capital social frágil, por la baja participación de los productores asociados en las decisiones de la cooperativa y por el escaso nivel de acceso a las informaciones elementales, como la situación financiera y contable de esta organización. El relato de uno de los entrevistados expone, de forma gráfica, tal dificultad:

Pero yo te digo que participo de las últimas, de los últimos 15, 20 años de casi todas las direcciones. Ya pedí para que no me convidasen [invitasen], para que no me convidasen, para que no me nombrasen o no me colocasen a la fuerza. No, tú eres del consejo, vas a tener que ir, no hay quien quiera. Y cuando tú haces una asamblea y convocas a todos los asociados, que hoy deben de ser en torno de trescientos asociados, todavía, comparecen en una asamblea unos diez, doce, quince. (Cooperativista 3)

Además de la baja participación, el número de socios muestra un claro declive. Datos de los avisos de convocatorias del año 2012 para asamblea general indican un cuadro social constituido por 850 miembros. Seis años más tarde (2018) este número se vio reducido a 505 socios, con una caída del $41 \%$ en el número de productores cooperativistas. Las entrevistas revelan que entre los principales factores consta la propia falta de incentivo a la producción, además de problemas relacionados con el abigeato (hurto de ganado). Otro factor importante es el avance de los monocultivos (soja, maíz, arroz) que ocupan espacios antes utilizados por la ovinocultura, lo que provoca que muchos productores arrienden sus campos y pasen a vivir de la renta generada por la cesión de sus tierras, sobre todo la que se destina al plantío de la soja.

Otro punto de constante preocupación, en lo que se refiere a la organización colectiva, es la falta de identificación de los socios con la cooperativa. Tal vez sea este uno de los principales desafíos a ser superado, pues acarrea comportamientos nocivos de los propios socios en relación con el sujeto colectivo. Son innumerables los relatos que demuestran una actuación oportunista por parte de asociados que, al percibir una oportunidad de negocio más atractivo, destinan su propia producción para los barraqueiros (comerciantes de lana) en detrimento del compromiso asumido con la cooperativa. Según nos informa uno de nuestros entrevistados:

Hay asociados que solamente quieren beneficiarse en el buen momento, hay otros asociados que nunca quitaron el pie. Incluso con el precio menor nos entregan toda la producción de lana, siempre fueron así, entonces, qué bueno sería si hubiese más asociados de este tipo, ¿no es verdad? (Cooperativista 2) 
Este tipo de acción, pautada esencialmente por un cálculo de costo/beneficio individual, es la característica básica de una índole típicamente individualista e inmediatista que prepondera en aquello que Putnam (2009) denomina "regiones menos cívicas", en las que intereses individuales se sobreponen a intereses colectivos. Otro productor también critica la actitud de algunos socios, atribuyendo este comportamiento a un trazo de conducta arraigada en la región:

Infelizmente es así, en la hora mala del tipo entregar lana, estas cosas, son muy pocos los que son socios. Es una pena, porque el cooperativismo es una cosa muy buena, es una pena que las personas no 5lo sean. El problema es que nuestra cultura de aquí de la frontera es muy complicada, aquí en nuestra región, aquí es terrible. (Cooperativista 1)

En el extremo opuesto están la versatilidad y la agilidad de los barraqueiros que, empleando el artilugio de efectuar el pago de la lana en metálico, usan su poder de negociación para sacar el máximo provecho junto a los ganaderos. El frágil espíritu cooperativo se suma a la imposibilidad de que la cooperativa pueda asegurar condiciones similares, a sus asociados, a las dadas por los barraqueiros. En el plano local hay una disputa constante entre estos dos frentes en la adquisición del producto. Además del pago en efectivo, hay momentos en los que el precio ofrecido por el barraqueiro es mejor que el que ofrece la cooperativa. Es sabido que uno de los pilares fundamentales que sustenta el funcionamiento de las organizaciones colectivas es la confianza y el compromiso con la organización, aspectos que se muestran vacíos dentro de esta lógica que aquí destacamos.

La cuestión organizacional es un tema que apareció en las entrevistas de una forma muy clara y recurrente. Los productores son conscientes de que tienen dificultades para pensar la cadena productiva como un todo integrado y constituido de diversos eslabones que unen el mundo rural y la cooperativa, el campo y la ciudad, la cultura y la propia identidad. El testimonio a continuación lo evidencia:

Mira, lo que veo es que nosotros, la cadena productiva, necesitamos organizarnos mejor. Lo que nos hace falta no es la calidad, sino organización. Esto es lo que más nos hace falta. Los líderes y toda la gente precisan organizarse. En cooperativas, las industrias necesitan organizarse en cadenas, nosotros tenemos que lograr un trabajo organizado como hacen los uruguayos. (Cooperativista 4)

Otra dificultad es la falta de capital de giro en la Cooperativa, lo cual acaba por restringir la capacidad de atender la demanda de los productores de forma rápida y eficaz. La cantidad de lana recibida declina cuando estos cooperativistas desvían su producción para los aventureros que actúan en el sector. No es raro que los ovinocultores conozcan los perjuicios al actuar de este modo. Tal práctica acaba por generar un ciclo vicioso que se inicia en el comportamiento del socio y se desdobla en una incapacidad constante de generar caja para comprar la lana producida en la región. Como bien advirtió Putnam (2001), la existencia de confianza elimina la necesidad de que se creen contratos para mediar las relaciones, algo que se convierte en un aspecto crucial para el funcionamiento de la organización en cuestión.

La lana es un activo genérico (Benko y Pecqueur, 2001) que no posee un gran valor de trueque en los mercados, y que presenta una escasa diferencia en términos de calidad en el modo como el sector se encuentra localmente organizado. Además, la calidad y el grado de finura de la fibra de lana producen variaciones en el precio de venta en mercados más exigentes. En el método actualmente adoptado para enfardar la lana existente en las propiedades rurales, velos distintos son colocados en la misma bolsa para el almacenamiento. Este proceso genera una contaminación en la lana, ya que las fibras de diferentes calidades y razas son mezcladas durante el proceso. Otro punto de contaminación es el propio material con que la lana es estocada, ya que los hilos de nylon usados en el proceso de atadura se unen a los vellones de forma inadvertida. Tales mezclas impiden que el producto comercializado por la cooperativa logre un patrón de calidad y, consecuentemente, una mayor valorización por las industrias textiles.

Con un valor comercial bajo, son necesarios grandes volúmenes de comercialización para obtener un retorno financiero satisfactorio para los socios. Para superar este tipo de problema, la gestión actual está buscando implantar cambios en el proceso de manipulación de la lana en bruto. El nuevo método consiste en almacenar individualmente los vellones en aras de mantener la calidad del producto, de modo que este 
quede libre de contaminaciones. De esta forma, es posible agregar valor al producto y buscar una estrategia de diferenciación:

Mira, esto puede agregar un valor que puede en el futuro ir, dependiendo de estas lanas nobles, de 30 centavos de dólar en kilo a 1 dólar de más en kilo. Porque cuando vas a hacer un trabajo, cuando va para un tejido, hay una diferencia muy grande entre una lana Corriedale, por ejemplo, y una lana Merina. Una es extremadamente fina, la otra más bien gruesa. Entonces, en la elaboración de un tejido eso hace la diferencia, hace la diferencia. [...]. Entonces, al vender una lana con el 100\% de pureza, tú estás vendiendo la calidad que va a dar calidad al tejido. (Cooperativista 4)

La estrategia utilizada para hacer que la producción lanífera se convierta en un activo específico prevé la tentativa de creación de un proceso de certificado propio. Este camino contraría la tendencia global observada en los productos agroalimentarios (Sato, 2009) y emerge como un interesante camino para reestructurar las bases del comercio local, mediante un modelo de calidad adecuado a los mercados más exigentes. Sin embargo, esta es una proposición que debe aún ser acogida por la red de cooperativistas, sin la cual no se puede llevar adelante cualquier iniciativa en este sentido. La especificación de activos depende de la construcción de una mayor proximidad entre los individuos y las reglas de reciprocidad (Benko y Pecqueur, 2001). Este cambio de comportamiento es esencial para que tal iniciativa prospere y sea duradera. Por otro lado, esta iniciativa tiene un carácter vertical, proque es de arriba hacia abajo y no brota desde la base de los asociados. De acuerdo con Putnam (2009, 185): "Un sistema vertical, por más ramificado y por más importante que sea para sus miembros, es incapaz de sustentar la confianza y la cooperación social". Así, es necesario que los productores vislumbren oportunidades en esta nueva práctica y decidan adherirse a un proceso nuevo y desafiador, hecho que exigirá una dosis adicional de trabajo, iniciativa y compromiso.

\section{LA DINÁMica de LA ARTESANÍA DE LANA EN JAGUARÃo - RS}

La Asociación de los Artesanos de Jaguarão surgió en el 2004 con el objetivo de acercar a aquellos que trabajaban con la artesanía y organizar mejor el comercio de sus artículos. El foco principal de la asociación, desde su fundación, son los trabajos hechos con lana ovina. Tal práctica está fuertemente conectada con el mundo rural y con las familias de ganaderos locales. Mujeres experimentadas elaboraban boinas, pulóveres, ponchos y otros artículos que inicialmente servían básicamente para vestir a los miembros de la familia y, eventualmente, para venta a terceros.

El grupo inicial que constituyó la organización estaba compuesto, en buena parte, por mujeres ligadas a la ganadería, las cuales poseían vínculos recíprocos de amistad y que aprendieron este oficio en la convivencia doméstica desde la más tierna edad. Con la organización en funcionamiento, este "saber-hacer", que antes era transmitido a través de las generaciones y dentro del núcleo familiar, pasó a ser institucionalizado, de modo que el conocimiento empezó a ser transmitido y compartido por medio de cursos ofrecidos por las artesanas fundadoras. La enseñanza orientada a despertar las habilidades de cardar, hilar, hacer croché, tejer y los trabajos en Jacquardson parte de una importante iniciativa que crece en la región animada por el reconocimiento público. El Jacquardes el trabajo de mayor notoriedad; es confeccionado en croché otejido, y es posible hacer dibujos con diferentes colores de lana, lo que les da un alto valor agregado a las piezas producidas.

Por supuesto, los productos son desarrollados individualmente y usualmente son comercializados mediante cadenas cortas, a través del contacto directo y personal entre la artesana y el comprador de los artículos. Son tres los principales canales utilizados. El primero se da en la propia sede de la organización, que funciona como espacio para impartir los cursoso como punto de venta de productos de sus asociados. En este caso, la artesana debe reservar el $30 \%$ del precio de venta para costear los gastos de la organización. El segundo canal son los ateliers, que funcionan en las propias casas de las artesanas; con él, ellas pueden quedarse con el monto total de la venta. Las ferias y exposiciones constituyen el tercer canal de comercialización. Con 
auxilio de la Emater (agencia oficial de extensión rural), las artesanas pueden exponer y vender sus productos fuera del municipio, divulgando su obra en exposiciones y certámenes que a veces conceden premios a los artículos confeccionados.

El reconocimiento del grado de excelencia de los artículos llevó a la organización a expandir significativamente su número de asociados. Los premios recibidos en ferias cruzaron las fronteras e incluso se llegó a una tentativa de reconocimiento del Jacquardcomo patrimonio inmaterial por parte del Instituto del Patrimonio Histórico y Artístico Nacional (IPHAN). Tal iniciativa se dio en el 2013 e involucró a la Prefeitura Municipal (Ayuntamiento), Emater y a la propia Asociación de Artesanos. Mientras tanto, esta organización comenzó a enfrentar dificultades en los últimos cinco años. La mayor de ellas corresponde a las divisiones internas que conllevaron una significativa disminución en el número de asociados. Encontrar una salida a estos problemas no fue una tarea fácil sino lo contrario, pese a que culminó con el surgimiento de una segunda asociación (disidente):

Allí, la gente, está todo bien, porque a estas alturas ya debe hacer unos diez años, yo creo. En aquel tiempo era otra experiencia, era mejor. El personal estaba más unido también. Ahora ya es diferente, ahora esta asociación que está ahí, entraron 50 y salieron 40. Es así, y cambia mucho. Hasta de presidentes. Allí tiene mucha gente que salió. (Artesana 2)

Con la reducción en el número de artesanas cayó también el volumen de ingresos exigido para costear los gastos, hecho que ocasionó la necesidad de cambiar el local de la sede. El nuevo punto comercial tiene menor visibilidad y flujo de potenciales compradores de los artículos, lo cual impacta en el volumen de ventas realizadas en la sede de la asociación. Ante esta situación, el compromiso colectivo acaba siendo sacrificado por los intereses personales:

Fuera de la asociación, nosotros no tenemos gastos: si vendemos, se vende. Si no se vende, no tienes que estar pagando una mensualidad, ¿no es verdad? Nosotros pagamos mensualidad en la casa donde tenemos las artesanías y pagamos el 30\% de lo que vendemos. Entonces, nosotras aquí, el garaje es mío, de mi casa, ¿no es verdad? Si vendemos, vendemos. Si no vendemos, no tienes gastos, ¿no es cierto? Para nosotros, está bien. (Artesana 1)

El nuevo grupo está formado por artesanas más jóvenes, las cuales habían entrado por medio de los cursos ofrecidos y del aprendizaje que asimilaron. Al salir de la Asociación construyeron un nuevo grupo en las dependencias del Centro de Economía Solidaria (CES). Este grupo está formado por artesanas más jóvenes y abiertas a las innovaciones, como en el uso de las redes sociales para divulgar sus productos y acceder a nuevos mercados. Este es uno de los puntos de divergencia con las artesanas que crearon la asociación original: Y yo, como se dice, yo y las más nuevas queríamos innovar, queríamos hacer la asociación crecer, queríamos más artesanos dentro, trabajando y ahí ¿qué fue lo que ocurrió? Ahí, comenzaron a chocar de frente conmigo, ¿verdad? (Artesana 10).

Tal aseveración converge con lo que afirma la Artesana 08: "Ellos estaban todavía como antiguamente, ellos querían la formalidad siempre del pasado. Y nosotros, yo, la G. y la A, nosotros teníamos esta voluntad de ir más para adelante, de innovar”. Diferencias de motivación y de intereses fueron decisivas en esta ruptura. Las artesanas que forman parte de la Asociación de los Artesanos tienen su vínculo con la artesanía, en cuanto ocupación y actividad que proporciona ocio y entretenimiento Venden sus piezas pero este no es el único factor motivador para insertarse en la organización, pues este espacio es también un local de socialización y de compartir experiencias. En palabras de una de las asociadas:

Yo creo que es importante, porque aquí tenemos un intercambio de conocimientos. AM [acrónimo] tiene mucha práctica en la creación, nosotros ya pasamos por eso también, entonces conversamos más o menos los mismos asuntos, tenemos el mismo placer en conversar, ella hace un trabajo, yo ya hago otro, ya llega una alumna. Entonces, esta tranquilidad, esta cosa social es muy importante, es una cosa muy buena ¿no es cierto? Si hay que ayudar, se ayuda. Ahora la hilandera vino y me trajo una lana que ella misma hiló, después llega una que quiere que yo la enseñe y le explique un trabajo que ella quiere comenzar, así, el intercambio de conocimientos y nuestra amistad siempre se alimentan de eso, es muy importante porque nuestra amistad es la amistad de 50 años (Artesana 6) 
Por otro lado, las artesanas reunidas en torno al CES (Centro de Economía Solidaria) poseen un interés mayor en la comercialización de sus productos. Estas artesanas aprendieron el artesanado por una necesidad de generar renta y no por ser una costumbre familiar heredada. La falta de interés en compartir propósitos comunes hace que estos sujetos que constituyen el grupo no se encuadren dentro de una identidad común. En este contexto, la tendencia compartir se orienta más en el sentido de favorecer el intercambio comercial e impulsar las ventas de los participantes.

Estos vínculos son importantes porque posibilitan la conexión entre círculos sociales diferentes, lo cual permite establecer puentes entre las redes; ello aumenta el contacto de los miembros del grupo con otros universos y hace que se expanda el acceso a la información. Sin embargo, lo que se observa en el campo es la construcción de "muros" y no de "puentes". La ayuda mutua se produce dentro de cada grupo, pero no traspasa sus límites. Según Fukuyama (2002), la solidaridad construida internamente en un grupo puede generar hechos externos negativos y causar que los están afuera sean rechazados. En este sentido, parte de la capacidad de articulación se escapa con la fragmentación de estos actores. Así, destaca Putnam (2009, 174): "Cuando los actores son incapaces de asumir compromisos entre sí, ellos tienen que renunciar - aun a su pesar- sin embargo, racionalmente, a muchas oportunidades de provecho mutuo". El testimonio siguiente es emblemático al señalar la actuación poco orientada a la colaboración con las artesanas que no participan del círculo de proximidad:

\begin{abstract}
Mira, infelizmente aquí es así, 'ojo por ojo'. Infelizmente es así. Hay algunos que tienen un ojo mayor que otro, es cada uno para su lado ¿entendiste? A veces unos queremos, pero otros no quieren. Porque a veces hay alguna cosa, lana en la asociación para ir a tal lugar que es solo el trabajo de Jacquard, ellas podrían hasta venir aquí, llevárselo al costoY si ellos allí no tienen un trabajo o no tienen, por ejemplo, una pala ruana, un jersey, ellos no tienen lana, ellos tampoco lo mandan para acá. Yo los mando, algunas veces los mando, cuando no tengo alguna cosa yo digo, no allí en la asociación tienen. Indico, pero ellos no nos indican. Para los otros, ellos no indican a nadie èverdad? Sólo quieren para el bloquecito de ellos allí. (Artesana 1)
\end{abstract}

Otros factores, como la edad avanzada de las artesanas y la imposibilidad de Emater de seguir auxiliándolas en las ferias y exposiciones, también han dificultado el mantenimiento de la organización original. Tales aspectos se suman a la falta de interés de los jóvenes en aprender el artesanado de la lana. En general, los cursos suministrados son para mujeres en la franja de los cuarenta años. Este movimiento preocupa, en el sentido de la perpetuación de esta práctica tradicional. No por el simple mantenimiento de una tradición sino por percibir en ella un fenómeno que puede inducir dinamismo a la región y generar renta para los actores que se involucren en los procesos productivos.

Los productos artesanales confeccionados con lana ovina demuestran un gran potencial, como activos específicos del territorio (Benko y Pecqueur, 2001). La alta calidad y singularidad de las piezas, premiadas por las innumerables distinciones en concursos, constituyen un interesante activo que merece ser reconocido como tal. Tratándose del Jacquard, la diferencia es todavía mayor, pues según las artesanas locales, los trabajos en esa línea sólo se encuentran en Jaguarão. Según Sutter et al (2015), las fibras orgánicas (algodón, lana y seda) sobresalen en los mercados de nicho, a través de una narrativa engarzada a la sustentabilidad, la cual permite una diferenciación y una singularidad que demandan los mercados más exigentes. Otra posibilidad interesante es la inclusión del turismo como elemento dinamizador. Cunha (2012) demuestra que iniciativas orientadas a la manufactura de la lana tienen un potencial turístico en lo que la autora llama "artesanado de referencia cultural”. En este sentido, la diferenciación es conseguida a través de un llamado a la cultura local. Para esta autora, tales iniciativas demandan un involucramiento mayor por parte del poder público local y regional, en el sentido de apostar por valorar la identidad regional.

\title{
CONSIDERACIONES FINALES
}

La ovinocultura orientada a la producción de lana está ante un momento crítico. El declive constante de la producción y el avance de los cultivos sobre áreas antes reservadas a la ganadería extensiva se inscriben 
como amenazas de gran calado para una actividad secular en esta región de la pampa brasileña. No se trata sólo de ampliar la renta a sectores de la población que encuentran dificultades de inserción en el mundo del trabajo. La cuestión es mucho más amplia y compleja, cara a los desafíos que se presentan para regiones marcadas por la crisis de oportunidades y el aislamiento, como es precisamente el caso de Jaguarão. Los activos específicos en cuestión pueden contribuir como medios para la puesta en marcha de estrategias de valorización y ampliación de oportunidades para la población local.

En lo que se refiere a la Cooperativa Mauá, el proceso de dar fe de la pureza de la fibra puede convertirse en una alternativa eficaz para revertir el momento desfavorable que vive dicha organización. Sin embargo, se trata de una condición necesaria, pero no suficiente, para enfrentar las dificultades del sector. Permanece, además, el desafío de que los ovinocultores apoyen esta idea para que ella se materialice, así como en el sentido de recuperar la relevancia del concepto de cooperación. Para las artesanas locales, el desafío parece el de hacer la conexión con los compradores, ya que la aceptación de sus productos en los mercados nicho se muestra como muy prometedora.

La fragilidad del capital social en la región evidenció ser la principal barrera a ser superada para que estas actividades puedan progresar. La actuación individualista es un obstáculo para la construcción de relaciones de confianza y para erigir puentes entre los actores sociales que permitan, a su turno, la apertura de nuevas oportunidades. En estos términos, es muy difícil delinear y conseguir objetivos de forma conjunta sin la existencia de un tejido social cohesionado y dispuesto a cooperar entre sí. La carencia de políticas públicas de incentivo también es otro factor que perjudica la articulación dentro de esta cadena productiva.

$\mathrm{Al}$ realizar el presente trabajo tenemos claro que la calidad es un concepto multifacético que va más allá de simples atributos tangibles de determinado producto o artículo destinado a satisfacer las necesidades de determinados tipos de consumidores o públicos interesados. La calidad está ligada a la fortaleza de los vínculos que unen actores en torno a procesos de producción, elaboración, trasformación, pero también a una identidad cultural forjada a veces a lo largo de siglos. La calidad se sostiene en valores éticos y normas pactadas entre personas que comparten una misma cultura y compromisos de medio y largo plazo. Esto no quiere decir que no existan conflictos, mucho menos que no haya narrativas en disputa.

Lo que está en juego es sobre todo la posibilidad de construir itinerarios que favorezcan la expansión de los horizontes de las personas y de las instituciones a las que están vinculadas. Finalmente, pero no menos importante, se trata de convertir la experiencia vivida en espacios de aprendizaje e innovación. Y si los aspectos que hemos aquí presentado ayudan a fomentar dicho debate, damos por sentadas las premisas que impulsaron la investigación realizada y la elaboración de este artículo.

\section{Agradecimientos}

Este trabajo no hubiera sido posible sin el apoyo de varias organizaciones. El primer autor agradece el apoyo recibido de los productores de ovinos, la Cooperativa Mauá, las artesanas de Jaguarão y a todos los actores de esta localidad que gentilmente ofrecieron sus testimonios e informaciones. El segundo autor del trabajo agradece al Conselho Nacional de Desenvolvimento Científico e Tecnológico (CNPq) por la concesión de una beca de productividad (Proceso $n^{\circ}$ 305086/2018-90) durante la etapa brasileña de la investigación. Agradece, además, a la Coordenação de Aperfeiçoamento de Pessoal de Nível Superior (CAPES), por la Beca de Profesor Visitante Sénior (por medio del PROGRAMA PRINT-CAPES), que hizo posible que realizara la misión científica (Proceso $n^{\circ} 88887.363956 / 2019-00$ ) junto al Instituto de Estudios Sociales Avanzados (Córdoba), órgano perteneciente al "Consejo Superior de Investigaciones Científicas de España”, al cual extiende su gratitud. 


\section{REFERENCIAS}

Abramovay, R. (2000). O capital social dos territórios: repensando o desenvolvimento rural. Economia aplicada, 4(2).

Abramovay, R. (2004). Entre Deus e o diabo: mercados e interação humana nas ciências sociais. São Paulo: Tempo Social, 16(2).

Acampora, T. y Fonte, M. (2007). Produtos típicos, estrategias de desarrollo rural y conocimiento local. Opera, 7(7).

Belas, C. A. y Wilkinson, J. (2014). Indicações geográficas e a valorização comercial do artesanato em Capim-dourado no Jalapão. Sustentabilidade em Debate, 5(3).

Benko, G. y Pecqueur, B. (2001). Os Recursos de Territórios e os Territórios de Recursos. Florianópolis: Geosul, $16(32)$.

Bofill, F. J. (1996). Reestruturac\#a\#o da ovinocultura gau\#cha. Guaíba: Agropecuária.

Bresser-Pereira, L. C. (2014) Desenvolvimento, progresso e crescimento econômico. Lua Nova, 93.

Cunha, A. M. (2012). O artesanato, suas estratégias de comercialização e constituição enquanto produto turístico da agricultura familiar em Pelotas, Pedras Altas e Jaguarão-RS: os casos do ladrilã e das redeiras (Tesis de Maestría inédita). Universidade Federal do Rio Grande do Sul, Faculdade de Ciências Econômicas, Porto Alegre, Brasil.

Dallabrida, V. R. (2012). Da vantagem comparativa à vantagem diferenciadora: estratégias de especificação de ativos territoriais como alternativa de desenvolvimento. Desenvolvimento Regional em debate,2(1).

Dallabrida, V. R. (2016). Ativos territoriais, estratégias de desenvolvimento e governança territorial: uma análise comparada de experiências brasileiras e portuguesas. Revista Latinoamericana de Estudios Urbano e Regionales, 42(126).

Desimon, S. y Novello, I. (2013). Mudança no Quadro Social da Cooperativa de Lãs Mauá: do Estancieiro ao Pecuarista familiar. In: Cotrim, D. S. Gestão de cooperativas: produção acadêmica da ASCAR. Porto Alegre: EMATER/RS.

Fonte, M. y Ranaboldo, C. (2007). Desarrollo rural, territorios e identidades culturales. Perspectivas desde América Latina y la Unión Europea. Opera, 7(7).

Fukuyama, F. (2002). Social capital and development: The coming agenda. SAIS review, 22(1).

Furtado, C.(2013). Essencial Celso Furtado. São Paulo: Companhia das Letras.

García Canclini, N. (1990). Culturas hibridas Estrategias para entrar y salir de la modernidad. México D. F.: Grijalbo.

Instituto Brasileiro de Geografia e Estatística - IBGE. (2019). Sistema IBGE de Recuperação Automática - SIDRA (Censos Agropecuários). Disponible en https://sidra.ibge.gov.br

Latouche, S. (2014). Existirá uma vida após o desenvolvimento? Estudos de Sociologia, 2(16).

Maiorki, G. J. y Dallabrida, V. R. (2015). A indicação geográfica de produtos: um estudo sobre sua contribuição econômica no desenvolvimento territorial. Interaçôes, 16(1).

Morris, S.T. (2009). Economics of sheep production. Small Ruminant Research, 86 (1-3).

Ortega, A. C. y Matos, V. A. (2013). Território, desenvolvimento endógeno e capital social em Putnam e Bourdieu. Política \& Sociedade. 12(24).

Pecqueur, B. (2009). A guinada territorial da economia global. Politica \& Sociedade, 14.

Putnam, R. (2001). Social capital: Measurement and consequences. Canadian Journal of Policy Research, 2(1).

Putnam, R. (2009). Comunidade e democracia: a experiência da Itália moderna. Rio de Janeiro: Fundação Getúlio Vargas.

Rostow, W. W. (1961). Etapas do desenvolvimento econômico (Um manifesto não-comunista). Rio de Janeiro: Zahar Editores.

Sacco dos Anjos, F. (2016). Abordagem territorial e desenvolvimento: tópicos sobre a natureza de um debate inacabado. En R. M. BADALOTTI y D. COMERLATTO. Território, territorialidades e estratégias de desenvolvimento regional. (pp. 15-27) Passo Fundo: Editora IMED.

Sacco dos Anjos, F., Da Silva, F. N. y Pollnow, G. E. (2016). O sinuoso caminho de construção da qualidade na ovinocultura pampiana: o caso do cordeiro Herval Premium. Estudos Sociedade e Agricultura, 24(1). 
Sachs, I. (2005). Desenvolvimento e cultura. Desenvolvimento da cultura. Cultura do desenvolvimento. Organizações \& Sociedade, 12(33).

Sato, G. S. (2009). As novas regras para o mercado global: certificações de origem e qualidade para alimentos seguros. Internext, 4(1).

Sen, A. K. (2007). Desenvolvimento com Liberdade. São Paulo: Companhia das Letras.

Silva, D. A., Nelson, A. V. M. y Silva, M. A. R. (2017). Do Desenvolvimento como Crescimento Econômico ao Desenvolvimento como Liberdade: A Evolução de um Conceito. Desenvolvimento em Questão, 16(42).

Sutter, M. B., Galleli, B., Maclennan, M. L. F., Polo, E. F. y Correa, H. L. (2015). Brazil's fashion and clothing industry: sustainability, competitiveness and differentiation. Latin American Journal of Management for Sustainable Development, 2(3).

Tonietto, J. (2007). Afinal, o que é Terroir? Bon Vivant, Flores da Cunha, 8(98).

Veiga, J. E. (2005). Desenvolvimento sustentável: o desafio do século XXI. Rio de Janeiro: Garamond.

Viana, J. G. A. y Waquil, P. D. (2013). The evolution of sheep production in Rio Grande do Sul and Uruguay: a comparative analysis of structural change. Ciência Rural, 43(6).

\section{Notas}

1 Gaúcho es el topónimo del que nace o es originario del Estado de Rio Grande do Sul.

2 Los testimonios han sido traducidos al español por los autores del artículo. 